\title{
Assessment of airborne asbestos fiber concentrations in urban area of Tehran, Iran
}

\author{
Hossein Kakooei • Masode Yunesian • \\ Hossein Marioryad • Kamal Azam
}

Received: 1 December 2008 / Accepted: 10 February 2009/Published online: 5 March 2009

(C) The Author(s) 2009. This article is published with open access at Springerlink.com

\begin{abstract}
Air quality in ambient outdoor air has seldom been evaluated in Iran. Accordingly, we evaluated airborne asbestos fiber concentrations in the urban environment of Tehran, Iran between January 2006 and March 2007. The airborne fiber concentrations of 80 air samples collected from 40 different sites in five areas of Tehran were analyzed by energy-dispersive $\mathrm{X}$-ray analysis in combination with phase-contrast optical microscopy (PCM) and scanning electron microscopy (SEM). The geometric means of the airborne asbestos fiber concentrations were $3.4 \times 10^{-3}$ PCM f $/ \mathrm{ml}(0.1$ SEM f $/ \mathrm{ml})$ and $3.3 \times 10^{-3}$ PCM f $/ \mathrm{ml}(0.20$ SEM $\mathrm{f} / \mathrm{ml}$ ) according to areas and seasons, respectively. There were significant differences in the asbestos fiber concentrations between the areas and seasons $(p=0.02$; $p=0.04)$, respectively. In the areas, the average concentration was $3.4 \times 10^{-3} \mathrm{PCM} \mathrm{f} / \mathrm{ml}(0.1 \mathrm{SEM} \mathrm{f} / \mathrm{ml})$, which is considerably higher than those reported for the levels of asbestos in outdoor air in the USA and the urban environment of the Europe. The SEM analyses revealed that the fibrous particles consisted, approximately, of chrysotile $(60 \%)$, tremolite $(10 \%)$, anthophyllite $(10 \%)$, and non-asbestos fibers (20\%). We conclude that the high volume of traffic, industrial consumption of asbestos, and
\end{abstract}

\footnotetext{
H. Kakooei $(\bowtie) \cdot$ M. Yunesian $\cdot$ K. Azam

School of Public Health, Center for Environmental Research, Teheran University of Medical Sciences,

Tehran, Iran

e-mail: hkakooei@sina.tums.ac.ir

H. Marioryad

Yasuj University of Medical Sciences,

Yasuj, Iran

H. Marioryad

School of Public Health, Teheran University of Medical Sciences, Tehran, Iran
}

geographical and climate conditions are responsible for the high airborne asbestos levels in non-occupational environments in Tehran. Thus, it is to be expected that inhabitants of Tehran will suffer negative health effects due to exposure to asbestos airborne fibers.

Keywords Airborne asbestos concentration - Ambient air . Iran $\cdot$ Residential area $\cdot$ Tehran $\cdot$ Urban environment

\section{Introduction}

Asbestos is a generic term for a group of naturally occurring mineral silicates in various forms that are easily separated into long and thin, flexible fibers when crushed or processed (Kakooei and Kakooei 2007). These mineral silicates are divided into two sub-groups: serpentine (chrysotile), which is used as the most commonly form of asbestos, and the amphiboles (amosite, tremolite, actinolite, anthophyllite, and crocidolite). Asbestos has been used extensively in building and industrial materials, including insulation, automobile clutches and brakes, and asbestos cement products, such as well panels, roofing plates, ventilation ducts, water tubes, and sewage pipes. While asbestos is not volatile, small fibers and clumps of asbestos fibers may be released to ambient air as a dust (EPA 1985d), and the health risks of exposure to such fibers/dust have been studied and debated for many years (ACSH 2007). Asbestos fibers are recognized to be carcinogenic and responsible for a variety of malignant diseases, such as lung cancer and mesothelioma (Nicholson and Landrigani 1994). In 2005, 55 cases of an asbestosrelated malignant mesothelioma appeared in the Iranian Annual of National Cancer Registration Report (IANCRR 2005). Clinical and epidemiological studies have estab- 
lished beyond all reasonable doubt that chrysotile asbestos causes cancer of the lung, and malignant mesothelioma of the pleura and peritoneum (Nicholson and Landrigani 1994, Thomson et al. 1963); however, the effects of asbestos on the human body need further consideration (Camus et al. 1998; Peto et al. 1995).

The use of asbestos in Iran began in the 1950s, and by the mid-1970s it was being widely used in friction materials (Kakooei et al. 2007). Approximately 55,000 tons of chrysotile asbestos in was imported in 2007 (Mehrdad 2008). The use of asbestos in industrial applications in Iran has not declined in recent years nor has the manufacturing of asbestos products ceased. Although there has been one report of airborne asbestos concentrations in a brake lining manufacturing plant located in the suburbs of Tehran (Kakooei and Kakooei 2007), there have been no reports of asbestos at exposure levels in non-occupational environments.

Given this lack of data on asbestos levels in ambient air and the background of approximately 40 years of asbestos use in Iran, an assessment of ambient concentrations of airborne asbestos is urgently needed to provide the information necessary for developing effective management strategies. In Iran, there is currently no specific criteria for asbestos in environmental media, such as air, that directly relate to the public health risk of asbestos exposure. In addition, there are no relevant international standards for ambient or environmental asbestos exposures (WHO 1998). In urban areas, most ambient air concentrations range from $3 \times 10^{-6}$ to $3 \times 10^{-4}$ PCM f/ml, but they may reach up to $3 \times 10^{-3} \mathrm{PCM} \mathrm{f} / \mathrm{ml}$ as a result of local sources (Corn 1994; EPA 1991b; IARC 1977; Nicholson and Pundsack 1973; Selikoff et al. 1972). Two other investigations of asbestos in outdoor air in the USA reported levels of asbestos, with a median of $3 \times 10^{-4}$ PCM f/ml and mean of $5 \times 10^{-5} \mathrm{PCM} \mathrm{f} / \mathrm{ml}$ (WHO 1998).

The aims of this study were: (1) to determine airborne asbestos fiber concentrations by phase-contrast optical microscopy (PCM) and scanning electron microscopy (SEM) in Tehran urban (residential) areas; 2 to compare the concentrations of respirable fibers by season and between five main areas in Tehran; (3) to obtain data that will contribute to establishing background exposure levels to asbestos fibers level to refer for reference in studying the effects of the high volume of vehicular traffic in Tehran.

\section{Materials and methods}

Sampling and analysis

Ambient air samples were collected between January 2006 and March 2007. The residential areas of Tehran were divided into five large regions: (1) the north $(\mathrm{N})$, (2) south (S), (3) east (E), (4), west (W), and (5) center (C). Airborne asbestos was analyzed in 80 air samples collected from 40 different sites dispersed in the five areas of Tehran. To evaluate the seasonal variations in fiber concentrations, we collected air samples at the same sites in each of the four seasons. The samples were collected on membrane filters (Millipore type AA; pore size $0.8 \mu \mathrm{m}$; diameter $47 \mathrm{~mm}$; Millipore, Bedford, MA) using an open-face filter holder (model FP050/2; Schleicher and Schull, Dassel, Germany). Sampling was performed at a flow rate of $10 \mathrm{l} / \mathrm{min}$ using a suction pump (model IP 30L; Sibata Scientific Technology, Tokyo, Japan); sampling times ranged from 4 to $8 \mathrm{~h}$. The samples were obtained outdoors at a height of $1 \mathrm{~m}$ above the ground. Each of the air samples was assessed by PCM, and the results were confirmed with SEM. For the PCM measurements, the sampled filters were prepared and analyzed according to NIOSH method 7400 (NIOSH 1989). In this procedure, the filter is first treated to make it transparent and then analyzed by microscopy [phase contrast illumination, Walton-Bechette graticule (type G-22), magnification of 400-450×]. A fiber was defined as any particle longer than $5 \mu \mathrm{m}$ and with a length-to-diameter ratio of 3:1. Although the PCM method is relatively fast and inexpensive, it does not distinguish between asbestos and non-asbestos fibers, and it can not detect fibers thinner than $0.25 \mu \mathrm{m}$. The analytical sensitivity was approximately $0.01 \mathrm{f} / \mathrm{ml}$ of air sampled. Another portion of the $0.8-\mu \mathrm{m}$ pore size filter was prepared and analyzed according to the SEM method (detection limit $0.4 \mathrm{~F} / \mathrm{l}$ ) specified by the Asbestos International Association (AIA 1984). The SEM (model XL30; Philips, Eindhoven, the Netherlands) was used in combination with energy-dispersive X-ray analysis (EDXA) to identify asbestos during the analysis of some of the samples. The SEM method can detect smaller fibers than the PCM and also fiber type, but its accuracy for counting fibers is unacceptably poor due to the small area that can be scanned at high magnification. The SEM analysis usually images fibers $>0.2 \mu \mathrm{m}$ in diameter because it has contrast limitations (NIOSH 1994b).

The AIA air sampling strategy requires the direct counting of fibers with a diameter $>0.5 \mu \mathrm{m}$ and a lengthto-diameter ratio of $\geq 5: 1$.

Statistical method

Descriptive statistics were used for both PCM and SEM measurements of airborne fiber concentrations. The mean fiber concentrations are shown as geometric means. The fiber concentrations of the airborne samples between areas, seasons, and squares were compared by one-way analysis 
Table 1 Airborne asbestos fiber concentrations by areas

\begin{tabular}{llll}
\hline Area & Number of samples & \multicolumn{2}{l}{ Asbestos fiber concentrations (fiber $/ \mathrm{ml})^{\mathrm{a}}$} \\
\cline { 3 - 4 } & & PCM f/ml & SEM f/ml \\
\hline North & 16 & $4.0 \times 10^{-3}\left(1.8 \times 10^{-3}\right)$ & $0.243(0.11)$ \\
South & 16 & $3.2 \times 10^{-3}\left(1.6 \times 10^{-3}\right)^{*}$ & $0.195(0.09)$ \\
East & 13 & $2.5 \times 10^{-3}\left(1.6 \times 10^{-3}\right)^{* *}$ & $0.153(0.10)$ \\
West & 13 & $3.9 \times 10^{-3}\left(1.5 \times 10^{-3}\right)$ & $0.237(0.09)$ \\
Center & 22 & $3.4 \times 10^{-3}\left(1.9 \times 10^{-3}\right)^{* * *}$ & $0.206(0.11)$ \\
Total & 80 & $3.4 \times 10^{-3}\left(1.7 \times 10^{-3}\right)$ & $0.206(0.10)$
\end{tabular}

$* p=0.02, * * p=0.04$, compared with the northern and western areas of Tehran, respectively; ${ }^{* * *} p=0.04$ compared with the eastern area of Tehran

SEM, Scanning electron microscopy; PCM, phase-contrast optical microscopy

${ }^{a}$ Values are given as the geometric mean, with the geometric standard deviation given in parenthesis

of variance (ANOVA) and Post Hoc tests (multiple comparisons) using the SPSS software for Windows ver. 11.5 (SPSS, Chicago, IL).

\section{Results and discussion}

Air pollution conditions

Tehran, the capital city of Iran and the regional center of Tehran province, has more than 7 million inhabitants and occupies a surface area of about $700 \mathrm{~km}^{2}$ (Kakooei and Kakooei 2007). The city is hemmed in by the Alborz Mountains to the north, resulting in an increasing volume of pollutants being trapped over the city when the wind is not strong enough to blow the pollution away (Kakooei and Kakooei 2007). Air pollution is one of the most serious environmental problems in Iran, and a study published by Peimaneh (2002) reported that the Pollutant Standard Index

Table 2 Airborne asbestos fiber concentrations by distance from squares

\begin{tabular}{|c|c|c|c|}
\hline \multirow[t]{2}{*}{$\begin{array}{l}\text { Distance from } \\
\text { squares }\end{array}$} & \multirow[t]{2}{*}{$\begin{array}{l}\text { Number of } \\
\text { samples }\end{array}$} & \multicolumn{2}{|c|}{$\begin{array}{l}\text { Asbestos fiber } \\
\text { concentrations (fiber } / \mathrm{ml}) \mathrm{a}\end{array}$} \\
\hline & & PCM f/ml & SEM f/ml \\
\hline$<10 \mathrm{~m}$ & 25 & $3.8 \times 10^{-3}\left(3.2 \times 10^{-3}\right)^{*}$ & $0.22(0.19)$ \\
\hline$>50 \mathrm{~m}$ & 55 & $3.3 \times 10^{-3}\left(1.6 \times 10^{-3}\right)$ & $0.20(0.09)$ \\
\hline
\end{tabular}

${ }^{*} p<0.01$ compared with the point $>50 \mathrm{~m}$ from square

${ }^{a}$ Values are given as the geometric mean, with the geometric standard deviation given in parenthesis
Table 3 Airborne asbestos fiber concentrations by seasons

\begin{tabular}{llll}
\hline Season & $\begin{array}{l}\text { Number of } \\
\text { samples }\end{array}$ & $\begin{array}{l}\text { Asbestos fiber } \\
\text { concentrations (fiber/ml) }\end{array}$ & \\
\cline { 3 - 4 } & & PCM f/ml & SEM f $/ \mathrm{ml}$ \\
\hline Winter & 19 & $2.5 \times 10^{-3}\left(1.3 \times 10^{-3}\right)^{* *}$ & $0.155(0.08)$ \\
Spring & 20 & $3.0 \times 10^{-3}\left(1.2 \times 10^{-3}\right)^{* * *}$ & $0.180(0.07)$ \\
Summer & 18 & $3.7 \times 10^{-3}\left(1.7 \times 10^{-3}\right)^{* * * *}$ & $0.225(0.10)$ \\
Autumn & 23 & $4.3 \times 10^{-3}\left(2 \times 10^{-3}\right)$ & $0.262(0.12)$ \\
Total & 80 & $3.4 \times 10^{-3}\left(1.7 \times 10^{-3}\right)$ & $0.208(0.10)$ \\
\hline
\end{tabular}

${ }^{\text {a }}$ Values are given as the geometric mean, with the geometric standard deviation given in parenthesis

${ }^{*} p=0.04, * * p<0.001$, compared with summer and autumn, respectively; $* * * p=0.009$, compared with the autumn; $* * * * p<0.04$, compared with the winter

(PSI) indicated an unhealthy air condition in Tehran for 252 days in 1999 and 282 days in 2000. The Japan International Co-operation Agency (JICA) predicted that about $71 \%$ of air pollution in Tehran is produced from mobile emission sources (JICA 1997). indicating that a major cause of air pollution in Tehran is the exhaust from the approximately 2.5 million motor vehicles, including about 0.5 million motorcycles, that operate in an extremely congested road space (average vehicle speeds $<18 \mathrm{~km} / \mathrm{h}$ ), as well as the 70000 industrial units (Paimaneh 2002).

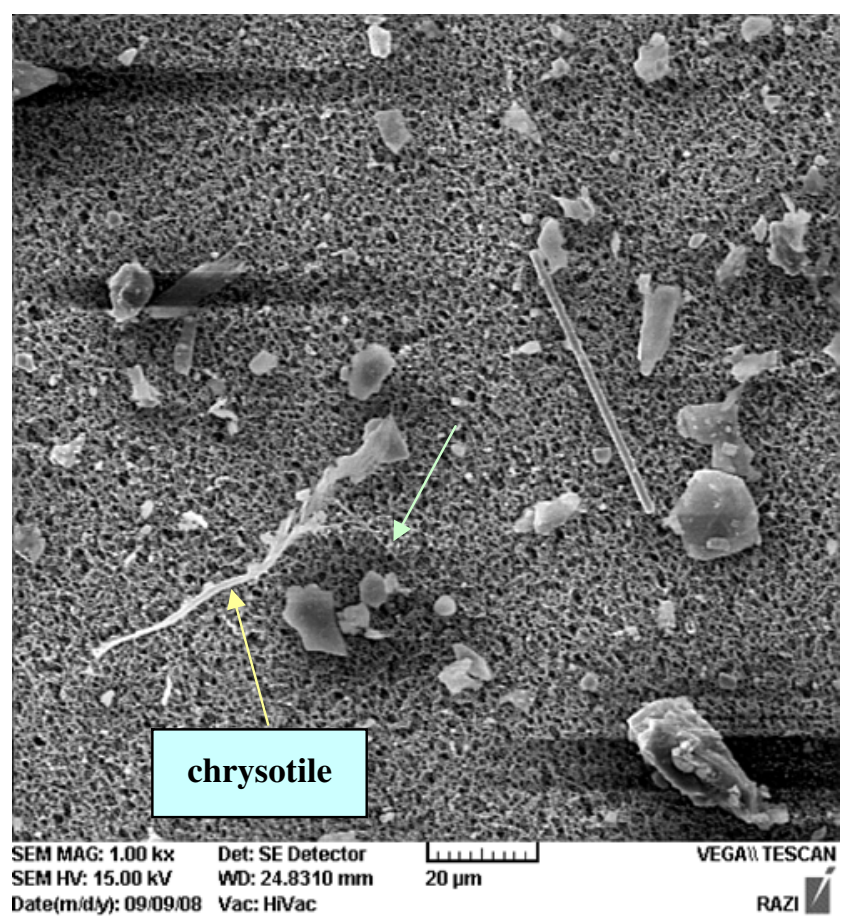

Fig. 1 Scanning electron microscope (SEM) image collected of chrysotile fiber 


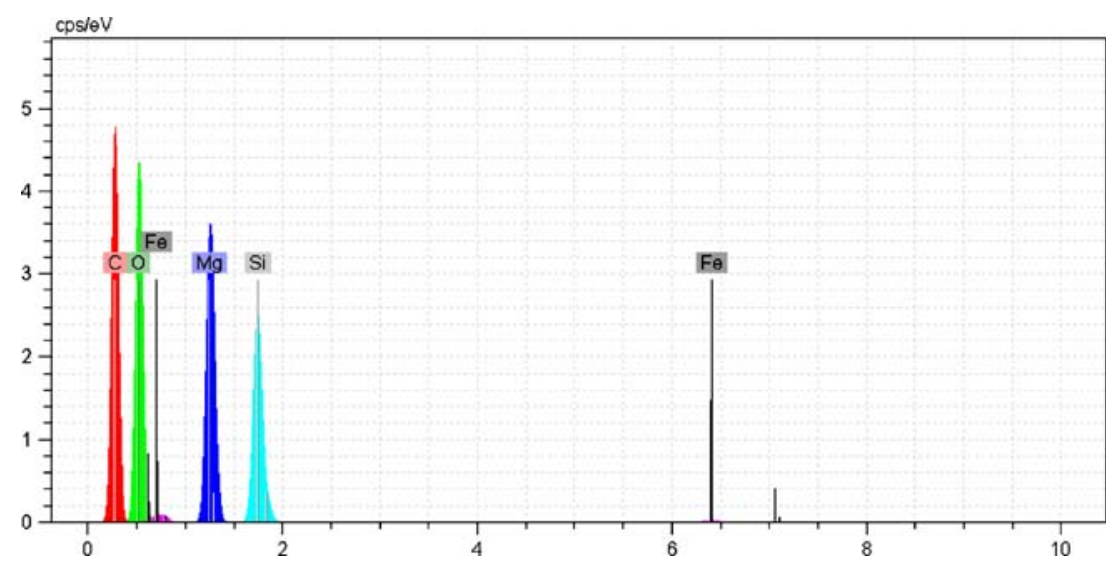

Fig. 2 Energy-dispersive spectrometry (EDS) spectrum collected from the air chrysotile fiber

Asbestos fiber concentrations by area

The geometric mean values of airborne asbestos in the samples collected from five areas of Tehran are given in Table 1. The highest geometric mean concentration of asbestos $\left(4.05 \times 10^{-3} \mathrm{PCM} \mathrm{f/} \mathrm{ml}\right.$ and $\left.0.24 \mathrm{SEM} \mathrm{f} / \mathrm{ml}\right)$ was found in the northern areas of Tehran, followed by the west, center, south and east areas. The geometric means of asbestos concentrations were significantly higher in the north of Tehran than in the other areas $(p=0.02)$.

As noted in previous studies, the concentrations of asbestos found in ambient air vary widely, and it is not

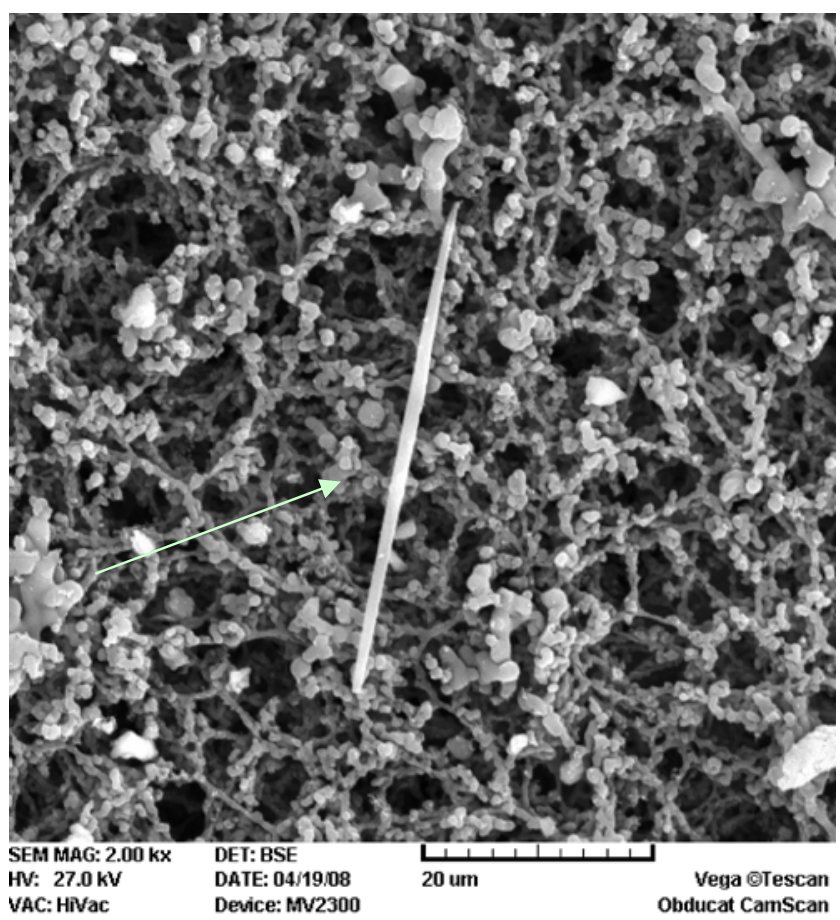

Fig. 3 SEM image collected from the air tremolite fiber possible to calculate non-occupational exposure levels accurately except on a site-by-site basis (HEI 1991; WHO 1998). In general, there are no relevant international standards for ambient or environmental asbestos exposures (WHO 1998). In urban areas, most ambient air concentrations range from $3 * 10^{-6}-3 * 10^{-4} \mathrm{PCM} \mathrm{f} / \mathrm{ml}$, but may range up to $3 * 10^{-3} \mathrm{PCM}$ f/ml (EPA 1991b; IARC 1977; Corn 1994). In 1991, the Health Effects Institute (HEI) reported on the levels of asbestos in ambient air worldwide, with estimated rural and urban levels of about $1 \times 10^{-5}$ TEM $\mathrm{f} / \mathrm{ml}\left(2 \times 10^{-7} \mathrm{PCM} \mathrm{f} / \mathrm{ml}\right)$ and $1 \times 10^{-4} \mathrm{TEM} \mathrm{f} / \mathrm{ml}\left(2 \times 10^{-6}\right.$ PCM f/ml), respectively (HEI 1991). In Tehran, the average concentration was $3.4 \times 10^{-3} \mathrm{PCM}$ f/ml $(0.1 \mathrm{SEM}$ $\mathrm{f} / \mathrm{ml}$ ), which is considerably higher (more than 68- and 45fold) than the levels of asbestos reported in outdoor air in the USA and the urban environment of Europe $\left(5 \times 10^{-5}\right.$ PCM f/ml and $2.2 \times 10^{-3}$ SEM f/ml; WHO 1998; Marconi 1989).

Table 2 shows the airborne asbestos fiber concentrations at the sites $<10 \mathrm{~m}$ and $>50 \mathrm{~m}$ distant from the squares, the neighboring and far points, respectively. The geometric means of airborne asbestos concentrations were significantly higher at the neighboring points (approximately in the squares) than at the distant points $(p<0.01)$. The geometric means of airborne asbestos at the neighboring points ranged from $5.4 \times 10^{-3} \mathrm{PCM} \mathrm{f} / \mathrm{ml}(0.32 \mathrm{SEM} \mathrm{f} / \mathrm{ml})$ to $2.4 \times 10^{-3}$ PCM f $/ \mathrm{ml}(0.14$ SEM f/ml), which is much higher than those estimated in other studies. In 1998, the World Health Organization (WHO) recommended $5 \times 10^{-5} \mathrm{PCM} \mathrm{f} / \mathrm{ml}$ as a reference value, corresponding to levels of asbestos in outdoor air in the USA (WHO 1998). In our analysis, the geometric mean asbestos concentrations exceeded $5 \times 10^{-5}$ PCM $\mathrm{f} / \mathrm{ml}$ in the areas and neighboring points.

In the ambient air samples, the geometric mean asbestos concentration at the points bordering on the square $(3.8 \times$ $10^{-3} \mathrm{PCM} \mathrm{f} / \mathrm{ml}$ ) was higher than those at the distant points $(p<0.01)$. Thus, it can be strongly suggested that the 


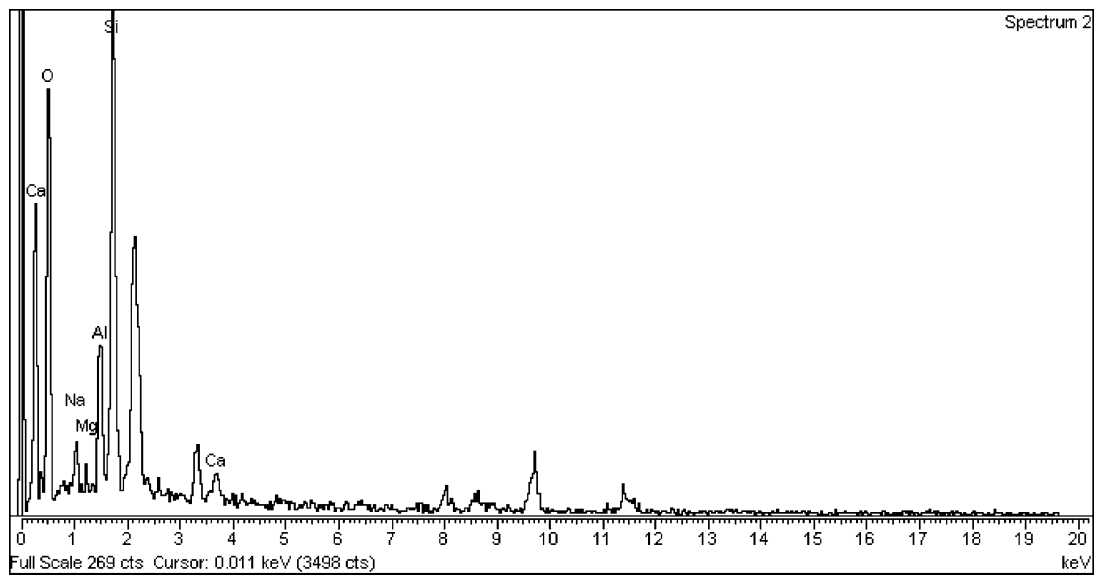

Fig. 4 EDS spectrum collected from the air tremolite fiber

density of airborne asbestos can be largely attributed to the high volume of vehicular traffic in the vicinity of squares.

Asbestos fiber concentrations by season

Table 3 shows the airborne asbestos fiber concentrations in each of the four seasons. The geometric means of the asbestos fiber concentrations were significantly higher in the autumn $\left(4.4 \times 10^{-3} \mathrm{PCM} \mathrm{f} / \mathrm{ml}\right.$ and $\left.0.26 \mathrm{SEM} \mathrm{f} / \mathrm{ml}\right)$ than in the other seasons $(p<0.001)$. As suggested by the results of the one-way ANOVA, season is an important determinant of airborne asbestos levels, with a season-significant

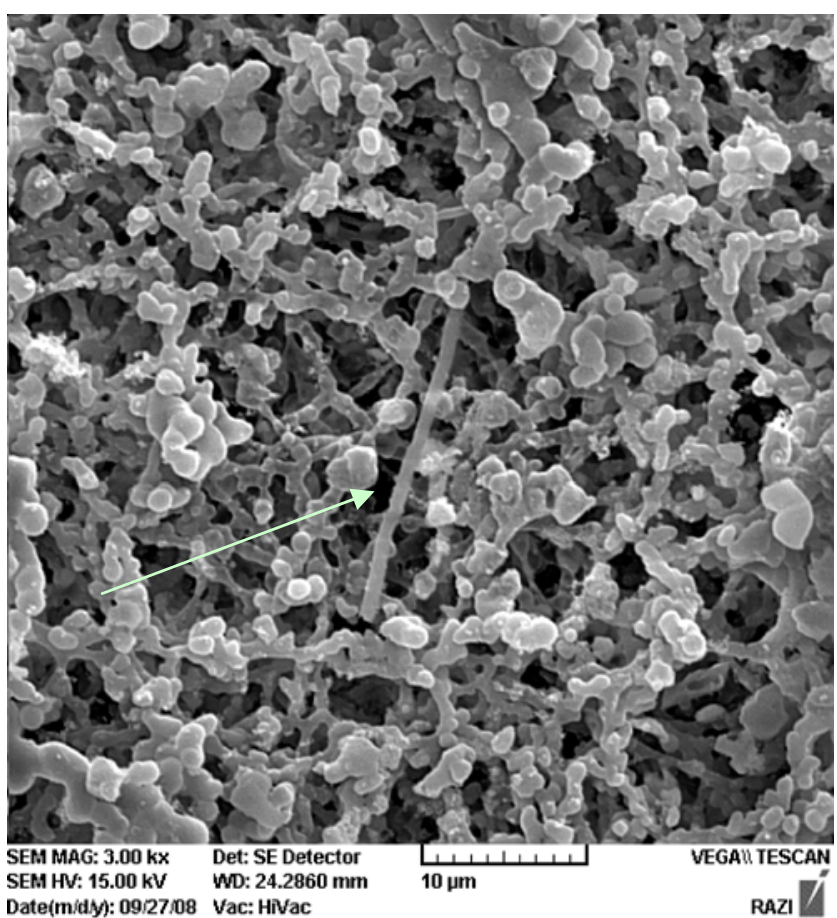

Fig. 5 SEM image collected from the air anthophyllite fiber $p$ value of 0.005 . The seasonal differences may be explained the more frequent presence of inversion layers and higher levels of urban transport during the autumn.

As noted above, the SEM analysis revealed that the fibrous particles in the urban environment consisted of chrysotile (60\%), tremolite $(10 \%)$, anthophyllite $(10 \%)$ and non-asbestos fibers (20\%). The SEM photographs in Figs. 1, 2, 3, 4, 5, 6 were obtained by a conventional SEM instrument with a metal evaporation coating and show airborne chrysotile, tremolite, and anthophyllite fibers in the ambient air. The chemical composition of the fibers was analyzed by energy-dispersive spectrometry (EDS) analysis (Figs. 2, 4, 6). Relative elemental concentrations can be estimated from the peak areas in the EDS analysis of the airborne asbestos. An example of an SEM image and EDS spectrum of chrysotile is shown in Figs. 1 and 2 in which the magnesium to silicon $(\mathrm{Mg} / \mathrm{Si})$ ratio is 1.0 . These data can be compared to the composition of standard reference chrysotile $(\mathrm{Mg} / \mathrm{Si}$ ratio 1.31$)$. The chemical profile of chrysotile asbestos consists of $\mathrm{Mg}$ and $\mathrm{Si}$ that are linked at the oxygen atoms. As shown in Figs. 4-6, tremolite has calcium instead of iron, while anthophyllite contains iron and the $\mathrm{Mg} / \mathrm{Si}$ ratio is 0.25 . It should be noted that chrysotile asbestos is used in automobile brakes, tremolite is a contaminant in talc and chrysotile ore, but anthophyllite fibers may be released to the outdoor air due to raw vermiculite (is a mica-like mineral) that is used in fireproofing, insulation, packaging, and automobile brakes.

Earlier studies on airborne asbestos concentrations in outdoor air in the Europe have shown higher concentrations in city areas; in comparison the amounts of asbestos measured in this study were higher than reported in these earlier studies (Marconi et al. 1989; Burdett et al. 1989). Kovalevskiy and Tossavaineh. (2005) reported that mean asbestos concentrations in the urban environment of Moscow were $2 \times 10^{-3} \mathrm{PCM} \mathrm{f} / \mathrm{ml}$, which are lower than 


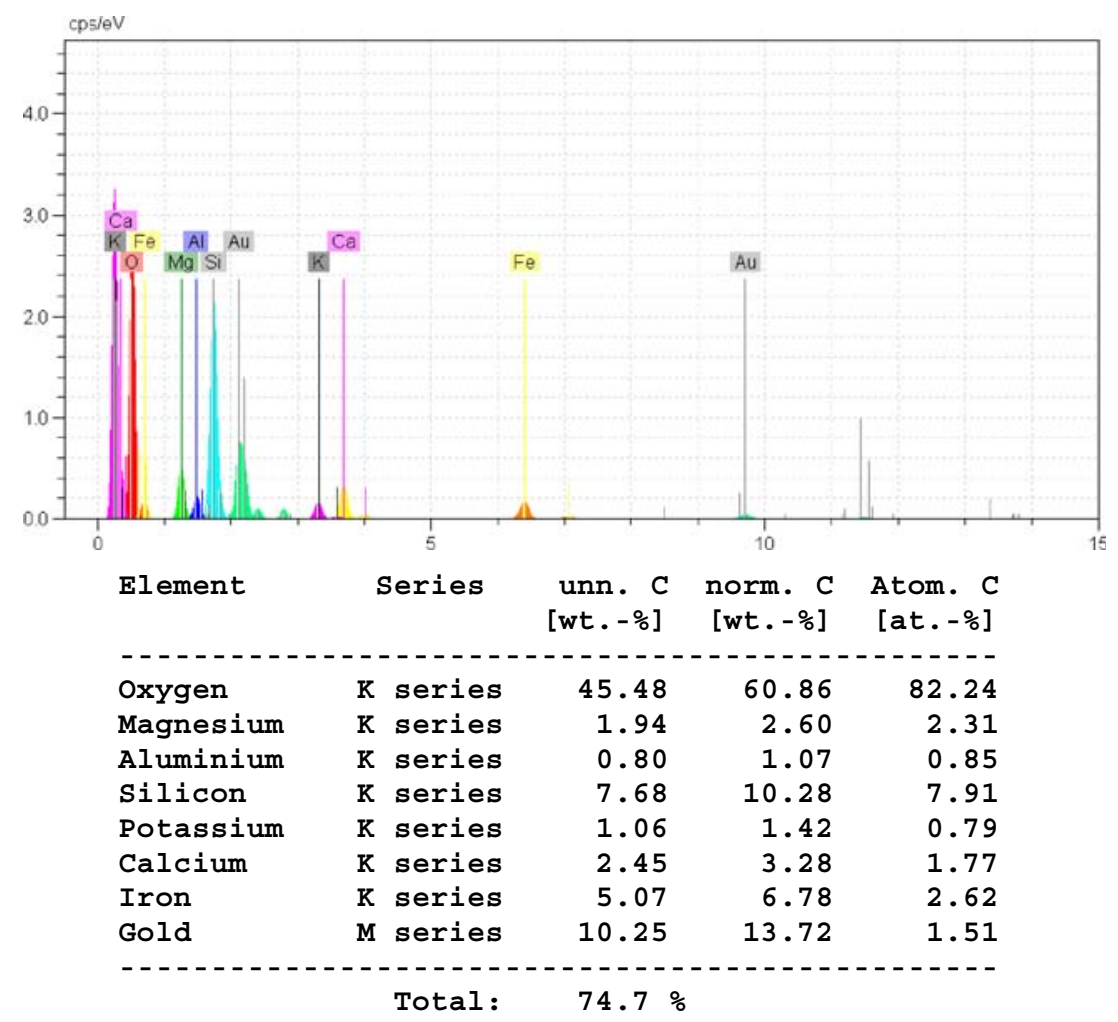

Fig. 6 EDS spectrum collected from the air anthophyllite

those found in this study. In general, the levels of airborne asbestos concentrations estimated in ambient air in our study $\left(2.5 \times 10^{-3}\right.$ to $\left.4.05 \times 10^{-3} \mathrm{PCM} \mathrm{f} / \mathrm{ml}\right)$ differ from those reported in other studies. The lower ambient asbestos levels of these other studies could be attributed to a better regulation of asbestos-containing materials, such as well panels, roofing plates, ventilation duct, water tubes, and sewage pipes. It has recently been recognized that the carcinogenicity of asbestos is strongly related to the size of the fibers sizes (Berman and Crump 2008). Therefore, it is important to know the size distribution of the fibers as well as the concentrations in occupational and non-occupational environments. As shown in Fig. 1, the diameter of the chrysotile fibers $(0.2-0.3)$ wass mostly smaller than that of the amphybole fibers $(0.3-0.5 \mu \mathrm{m})$. The SEM data in Tables $1-3$ are the concentrations calculated for fibers $\geq 5 \mu \mathrm{m}$ in length and $>0.2 \mu \mathrm{m}$ in diameter. We found differences in the amount of fibers approximately $5 \mu \mathrm{m}$ long between $10 \mathrm{~m}(0.026 \mathrm{SEM} \mathrm{f} / \mathrm{ml})$ and $>50 \mathrm{~m}(0.036$ SEM f $/ \mathrm{ml}$ ) distant from the squares. The geometric means of concentrations of fibers of the same length in the seasons were 0.037 SEM f/ml. Considering that $71 \%$ of air pollution in Tehran is produced by vehicle emissions (JICA 1997), our results strongly suggest that the high levels of airborne asbestos is largely attributable to the brakes and clutches of automobiles. In addition to the above finding, asbestos accumulates in human lungs for a lifetime, unlike other air pollution materials, such as carbon monoxide, sulfur dioxide, nitrogen dioxide, ozone and particulate matters $\left(\mathrm{PM}_{10}\right.$ and $\left.\mathrm{PM}_{2.5}\right)$. Consequently, the possibility of asbestos-related diseases in Iran are high given the high volume of vehicular traffic, industrial consumption of asbestos, and industrial units in urban areas.

\section{Conclusion}

Exposure to airborne asbestos fiber is generally higher in the capital city of Iran (Tehran) than in similar cities in developed countries. Asbestos fibers in Tehran were much higher-more than 68- and 45-fold higher-than those reported for the levels of asbestos in outdoor air in the USA and the urban environment of Europe, respectively. We conclude that the high volume of traffic, high industrial consumption of asbestos, and geographical and climate conditions are responsible for the high airborne asbestos in non-occupational environments in Tehran. Thus, exposure to asbestos airborne fibers are likely to have negative health effects on the inhabitants of Tehran. Considering that the numbers of vehicles on the roads in Tehran are increasing each year, the monitoring of airborne asbestos in the urban environment and the establishment of non-occupational exposure limits are strongly recommended. An alternative proposal is to implement national programs aims at banning the use of asbestos. 
Acknowledgements We would like to thank the Center for Environmental Research and deputy of research of Tehran University of Medical Sciences for funding this study.

Open Access This article is distributed under the terms of the Creative Commons Attribution Noncommercial License which permits any noncommercial use, distribution, and reproduction in any medium, provided the original author(s) and source are credited.

\section{References}

ACSH (American Council on Science and Health) (2007) Asbestos exposure: How risky is it? ACSH, Washington D.C.

AIA (Asbestos International Association) (1984) Method for the determination of airborne asbestos fibers and other inorganic fibers by scanning electron microscopy. AIA Health and Safety Publ RTM no 2. AIA, London

Berman DW, Crump KS (2008) A meta-analysis of asbestos -related cancer risk that address fiber size and mineral type. Crit Rev Toxicol 6:49-73. doi:10.1080/10408440802273156

Burdett GJ, Jaffrey S, Rood AP (1989) Airborne asbestos fiber levels in buildings: A summary of UK measurements. IARC Sci Publ 90:277-290

Camus M, Siemiatycki J, Meek B (1998) Non - occupational exposure to chrysotile asbestos and the risk of lung cancer. N Engl J Med 42:1565-1571. doi:10.1056/NEJM199805283382201

Corn M (1994) Airborne concentrations of asbestos in nonoccupational environments. Ann Occup Hyg 38:495-502. doi:10.1093/annhyg/38.4.495

EPA (Environmental Protection Agency) (1985) Environmental release of asbestos from commerial product shaping. EPA /600/ s2-85/0044. U.S. Environmental Protection Agency, Water Engineering Research Laboratory, Cincinnati

EPA (1991) Indoor-air assessment: Indoor concentrations of environmental carcinogens. EPA /600/8-90/042.NTIS No.PB91-193847. U.S. Environmental Protection Agency, Office of Health and Environmental Assessment, Research Triangle Park

HEI (Health Effects Institute) (1991) Asbestos in public and commercial buildings: a literature review and synthesis of current knowledge. Report of the asbestos literature panel. Health Effect Institute, Cambridge

IANCRR (Iranian Annual of National Cancer Registration Report) (2005) Iranian Annual of National Cancer Registration Report. Center for Disease Control Non-communical Deputy Cancer
Control Office, Ministry of Health and Medical Education Health Deputy, Tehran

IARC (1977) IARC monographs on the evaluation of the carcinogenic risk of chemicals to man: asbestos, vol 14. World Health Organization, Lyon

ICRS (2005) Iranian Cancer Registry System. Asbestos related cancer. ICRS

JICA (Japan International Co-operation Agency) (1997) The study on an integrated master plan for air pollution control in the Greater Tehran area, chapter 8, final report. JICA, Tokyo

Kakooei H, Kakooei AA (2007) Measurement of PM10, PM2.5 and TSP particle concentrations in Tehran, Iran. J Appl Sci 7:3081-3085

Kakooei H, Sameti M, Kakooei AA (2007) Asbestos exposure during routine brake lining manufacture. Ind Health 45:787-792. doi:10.2486/indhealth.45.787

Kovalevskiy E, Tossavainen A (2005) Asbestos fiber in the urban environment in Moscow. IOHA Pilanesberg: paper J5

Marconi A, Cecchetti G, Barbieri M (1989) Airborne mineral fiber concentrations in an urban area near an asbestos-cement plant. IARC Pci Publ 90:336-346

Mehrdad R (2008) Asbestos in Iran. International symposium of removal and transfer of asbestos in Asia. Seoul

Nicholson W, Landrigan PJ (1994) Asbestos: a status report. Curr Issues Public Health 2:118-23

Nicholson WJ, Pundsack FL (1973) Asbestos in the environment. In: Biological effects of asbestos. Proc Working Conference IARC. IARC Sci Publ 8:126-132

NIOSH (1989) Method 7400: Fibers. In: Niosh manual of analytical methods, 3rd edn. U.S. Department of Health, Education and Welfare, Cincinnati

NIOSH (1994b) Asbestos by TEM. In: Manual of analytical methods, 4th edn. U.S. Department of Health and Human Services, National Institute for Occupational Safety and Health, Cincinnati

Peimaneh H (2002) Air quality management in Tehran. In: Regional Workshop on Pollution and Health in Iran. Air Quality Control Company, Tehran, pp 1-8

Peto J, Hodgson JT, Mattews IR, Jones IE (1995) Continuing increases in mesotholioma mortality in Britain. Lancet 345:535-539. doi:10.1016/S0140-6736(95)90462-X

Selikoff IJ, Nicholson WJ, Langer AM (1972) Asbestos air pollution. Arch Environ Health 25:1-13

Thomson JG, Kaschula ROC, McDonald RR (1963) Asbestos as a modern urban hazard. S Afr Med J 37:77-85

WHO (World Health Organization) (1998) Chrysotile asbestos: Environmental health criteria. World Health Organization, Geneva 